Case Studies 



\title{
The International Journal of Wellbeing: An Open Access Success Story
}

\author{
Dan Weijers ${ }^{*}$ and Aaron Jarden ${ }^{\dagger}$ \\ *University of Waikato, daniel.weijers@csus.edu \\ ${ }^{\dagger}$ Auckland University of Technology
}

\begin{abstract}
Editors' Commentary
Academics have long had the advantage of access to university libraries and their expensive subscriptions to scholarly journals. Critics of traditional journal publishing have complained that placing science and scholarship behind a paywall limits its potential. One solution to this problem is the emergence of open access journals. In this chapter, authors Weijers and Jarden offer a case study of a platinum open access journal they founded: the International Journal of Wellbeing. In their discussion of this new journal they offer both philosophical and practical insights that guide their work. They also point to often overlooked issues regarding open scholarship. One of these is the huge numbers of unaffiliated faculty or faculty from non-Western universities, all of whom suffer barriers to access to expensive journals. The authors look to increasing openness of journals to solve this and other problems.
\end{abstract}

DW: There are not enough journals that publish interdisciplinary wellbeing research.

AJ: You're right. The few that do are choked up with submissions.

DW: We could create one, you know. There is free software for it.

AJ: That's a great idea. What would we call it?

How to cite this book chapter:

Weijers, D and Jarden, A. 2017. The International Journal of Wellbeing: An Open Access Success Story. In: Jhangiani, R S and Biswas-Diener, R. (eds.) Open: The Philosophy and Practices that are Revolutionizing Education and Science. Pp. 181-194. London: Ubiquity Press. DOI: https://doi.org/10.5334/bbc.n. License: CC-BY 4.0 
DW: What about the Australasian Journal of Wellbeing?

AJ: Why not the International Journal of Wellbeing?

DW: But, could we really make it thoroughly international?

AJ: Sure, and it would be more fun. We should ask all of the people we really admire to be involved - and they're everywhere.

DW: But, why would they get on board with this?

AJ: I can see a lot of benefits, and I think they will too.

DW: Let's grab a coffee and figure this out...

\section{The International Journal of Wellbeing: A caffeinated conception}

In 2010, over coffee, this is roughly how we-the authors of this chapter-began exploring the idea of creating the International Journal of Wellbeing (IJW $)^{1}$ - an online only, interdisciplinary journal. We were motivated by our beliefs in the value of interdisciplinary wellbeing research and the importance of making useful academic research available to everyone. We also both love a challenge! At the time, Aaron held a junior faculty position at the Open Polytechnic of New Zealand, and Dan was a PhD student at Victoria University of Wellington. Less than a year later, on January 31st, 2011, the IJW launched its first issue. So, how did two young academics from the far corner of the academic world create an online only journal that, five years after launch and 15 issues later, is a respected and widely read journal (with unsolicited submissions from leaders in the field and nearly 500,000 full text article views)? Although hard work, quality relationships, and luck undoubtedly had roles to play, the key to the IJW's success was, and still is, its open access publishing model.

After our initial conversation, we conducted research into the various business models for journals. It did not take long to discover that the costs for publishing an online only journal were tiny. Overhead costs are about US $\$ 1,000$ per year, and per article costs are about US\$200, which includes professional copyediting, layout, and proofreading. We were astonished to discover this, and quite appalled at the current cost of journal subscriptions, article download fees, and one-off author fees for making individual articles open access in otherwise pay-for-access journals. For example, at US\$39.95 plus tax per article (early 2016 price $)^{2}$, Springer would need five paying readers to recoup a reasonable per article cost of US\$200. Even better for Springer, the authors could pay US\$3,000 plus tax (early 2016 price) to make the article open access (free for everyone to read). ${ }^{3}$ For an independent journal that uses professional copyediting, layout, and proofreading services, that US\$3,000+ open access fee could cover the per article costs of fifteen articles. This begs the question, why so much? Springer and other academic publishers do add value, particularly with marketing, but they are also a profit-taking company with several layers of management. The truth behind most journal business models is that the vast majority of the hard work is done by academics. Thousands of hardworking academics find time 
to write, review, and edit for journals, often while juggling teaching and academic service responsibilities. Without those academics, the journals would fail, and with them, very little else is required for success. To be clear; it is not that Springer and other academic publishers do not add value-they do-it is just that they charge universities, academics, and others what we perceive to be a lot of money for added value that can easily be created in much cheaper ways.

The Internet has also played a huge part in all this, by making the dissemination of research orders of magnitude cheaper and more efficient than it was just 25 years ago; times have changed. One of the most important changes is the commitment of countless skilled people around the world, who create software and make it freely available for fun, and for the greater good. Governments and other organizations also play an important part when they fund open access and open source software initiatives. Most importantly for us, very high quality open source journal software is available for do-it-yourself journal publishers. We cannot thank enough the brilliant people at the Public Knowledge Project (PKP) and Open Journal Systems, as well as the US federal government for funding the opening up of academic research through the PKP. The software from Open Journal Systems allows even relatively techno-averse academics to do everything they need to in order to professionally manage and publish a quality academic journal.

\section{The case for open access}

With the knowledge that we only needed about US $\$ 5,000$ per year to setup and run a successful online only journal, we realized that we did not have to approach journal publishers; we could publish the journal ourselves. The idea of open access publishing was appealing to us because it seemed fairer and more in line with our view of the point of academia - the production of useful information for all. Fully open access journals (that make all content free to everyone immediately upon publication) can be read by anyone with an internet connection and a computer. We believe that it is important that useful research publications can be accessed by as many people as possible, and as soon as possible. There exist many inequalities in the world, and unequal access to the most recent academic research, especially on wellbeing, is a particularly pernicious kind of inequality since it could exacerbate other forms of inequality. For this reason, we are proud that the research in the IJW has reached people in 185 nations around the world.

\section{But who pays? Gold vs. platinum open access}

\section{Gold open access is not that open or fair}

Making quality academic research freely available to everyone is a laudable aim, but even with academics volunteering to do most of the work, someone still has 
to pay for various parts of the publishing process. Many open access business models get the authors to pay. It does not seem fair to us to require authors to pay for the privilege of publishing in a journal, especially since they do most of the work in the research publishing process - writing research-based articles that extend the global body of useful information. This author pays kind of open access is sometimes referred to as 'gold open access,' but as we'll argue, it is gold in a credit card kind of way, not an Olympic medal kind of way.

Proponents of gold open access might argue that the authors never have to pay out of pocket because their institutions pay for them. But this reasoning is of little solace to unaffiliated scholars, academics at underfunded institutions, and academics outside of the sciences (where author fees are not the norm, and so institutional funds for publishing fees are less readily available). Some publishers waive the author fee for their fully open access journals to authors from low and lower-middle income nations. When publishing in Springer journals, for example, authors from Bangladesh do not have to pay a fee, but authors from India do. This is a good start, but many authors from India will not be able to get institutional funding, nor will humanities-based authors from many highincome nations. Therefore, even though gold open access articles and journals can be read by everyone, not everyone who might want to can publish in gold open access journals. In this way, gold open access is not completely open. This lack of access to gold open access journals can prevent many unfortunate academics from getting their research widely read, and widely cited, making it harder for them to progress in their careers. And, since this is through no fault of their own, we suggest that gold open access author fees can unfairly impact on some academics career prospects.

Gold open access might also be unfair to the funders of academic research. Passing the author fee on to academic institutions seems unfair to the institutions, since it is the academic institutions that pay the academics, enabling the writing of articles in the first place. While academic institutions are the main producers and consumers of academic research, the main funder of academic research is often governments. Governments subsidize academic institutions and fund research granting organizations, like the National Institutes of Health, because citizens generally value research-led education and the economic and other benefits of new academic research. As a general overview, governments fund the creation of research (via research grants and university subsidies) and the publishing of research (through open access fees or university library subscription fees). However, in some cases governments could pay four times for a published piece of research: First by subsidizing the university that pays the wages of the researchers to produce research. Second, through a directly funded research grant. Third, by paying the gold open access fee to make the research publically available. And fourth, by subsidizing the many university libraries that pay for the access to the pay-for-access journal that the author-paid-open-access article happens to be in. It is certainly possible that that the funders (mainly governments), the producers (mainly academics), and 
the consumers (mainly academics) of academic research are getting fleeced by publishers, which seem to add a small amount of value and take a huge cut of the profits.

\section{Gold open access in action}

Consider the example of the online only Springer journal Applied Physics B. In 2015, Applied Physics B published 66 articles, averaging nearly eight and a half pages in length. By our calculations, the per article cost for professional copyediting, layout, and proofreading could easily be as little as US\$200 (our much longer articles cost us about US $\$ 200$ each). So, the total per article cost for the whole year of articles could be as little as US\$13,200. In 2015, 18 articles were gold open access, meaning that 18 authors (or their institutions or governments, depending on the particular circumstances) each paid up to US $\$ 3,000$ plus tax to Springer. That's up to US $\$ 54,000$ paid to Springer by authors in 2015 just for articles in Applied Physics B. Springer may well have higher per article costs than the US $\$ 200$ we estimated, and they certainly have much higher overhead costs than us (e.g., upper management salaries), but it would be surprising if Applied Physics B didn't make Springer a decent amount of money just from the gold open access author fees and related institutional open access agreements. Of course, Springer also profits from selling annual subscriptions to Applied Physics B and individual articles from it. The current institutional annual subscription rate for the online only journal Applied Physics B is US $\$ 7,050$ for the regular version and US $\$ 8,460$ for the enhanced version. ${ }^{4}$ We suppose that individual journal subscriptions are less common than subscriptions to bundles, so Springer probably receives less than US $\$ 7,050$ per subscription to Applied Physics B. Even so, on the conservative estimate that 100 institutions and companies have a subscription to Applied Physics B, Springer receives hundreds of thousands of dollars in revenue each year through sales of subscriptions to the online only journal. As we said, Springer does add value with its publishing, hosting, and marketing process, but is it worth it? If one government or academic institution stumped up less than US\$20,000 a year, then they could produce Applied Physics B to a similar standard. Why do governments and academic institutions (collectively) pay hundreds of thousands of dollars per year more than they need to? All told, gold open access doesn't seem all that open, or fair. It is OK, but something better is available, so golden open access is golden like a credit card, not like an Olympic medal.

\section{Platinum open access is open, fair, and the way of the future}

The editors of the IJW endorse platinum open access, which means we endorse publishing models that do not require readers or authors to pay. Platinum open access is more open than gold open access since, in platinum open access 
models, more people can contribute to the information. Platinum open access is also fairer than gold open access because academics who would otherwise have to pay their own author fees are not disadvantaged in this way, and because in platinum open access models, exorbitant publishing costs are not shouldered by those that have already funded the majority of the work. Platinum open access journals are usually funded by non-profit and charitable organizations, especially scholarly societies. Platinum open access journals can also be funded by academic institutions or self-funded through advertising revenue and donations. In general, academics are still doing most of the work, and they still pay most of the costs (or their institutions or governments do), but the costs are often dramatically lower. Some platinum open access journals are funded by academic societies and still published by for-profit publishers like Springer. ${ }^{5}$ We think that this may not be the best choice, depending on how much commercial publishers charge for their services. A likely better choice would be to publish platinum open access journals independently or in association with a university library, established academic association, or similar institution. After the initial challenges of setting up, editors would have more freedom over format, and much lower costs. Platinum open access is more open and fair than gold open access, especially when it cuts out the expensive publisher-middleman. Platinum open access is to gold open access what a platinum credit card is to a gold one.

Just imagine what it would be like if governments decreed that all government funded research must be published in platinum open access outlets by the year 2026. Journals that are not currently platinum would investigate how to become platinum. For-profit publishing companies would have very little to offer them, unless they incorporate inordinate amounts of advertising in their publications. But not many companies want to advertise to academics since we are not a very lucrative target market. For-profit publishers might try to strike up direct pay-per article contracts with governments, but this price-setting might discourage quality as publishers pressure editors to be more generous with their acceptance rates. We think that a better solution would be for university libraries to cut their journal subscription budgets by $10 \%$ every year, and used that money to join with or create university presses and publish journals themselves. Given the declining interest in paper-based books and periodicals, librarians are in need of exciting new projects, so they should leap at the opportunity. There will likely be competition between top universities to secure the most prestigious journals, meaning that the editors of those journals should be able to secure ongoing top quality services and support for their periodical. The incentives will remain largely the same; authors will want to publish in the best journals, journal editors will want to attract the best research, and institutions will want to be associated with the best research, such as when they publish a top journal or employ someone who publishes in top journals. The main difference will be that all academic research will be completely open and the costs to 
the funders of research (mainly governments) should be lower because a profittaking middleman has been removed from the process.

Why aren't governments already mandating that all government funded research must be published in platinum open access outlets? There are several possible reasons. Governments might be hesitant to be seen as restricting academic freedoms in any aspect of their work. Governments might not realize that most academics are unhappy with the current state of academic publishing. Governments might believe that forcing the academic market to comply with a platinum open access publishing mandate might create perverse incentives akin to the ones that have brought about the predatory open access journals that have proliferated in the last few years. Hopefully this book, and the advocacy of academics and other groups will help address these potential worries.

\section{How open?: Creative Commons licenses}

As we are sure readers are now well aware, not all open access is created equal. But the difference between gold and platinum open access is not the only important one. As academics as well as potential publishers, we realized that most academics are concerned to protect their intellectual property. For this reason, we wanted to make it clear that authors own the copyright to work published in the IJW, and we chose the Creative Commons license that gives authors the most protection, while ensuring the work can be used for all normal academic purposes without payment to the journal, the authors, or anyone else. As such the IJW uses the Creative Commons Attribution-Non Commercial-No Derivatives (CC BY-NC-ND) license. The attribution part of the license means that the work must always be explicitly described as being originally created by the authors. This is a standard protection for academic work. The no derivatives part of the license means that the work may not be re-versioned (imagine our open source software that you update and re-release) without the authors' permission. We believe that this offers an important protection for authors because it helps prevent third parties from changing the original work in ways that might reflect badly on the authors. Imagine changing a historical article about Hitler so that the authors appear to be endorsing, rather than merely reporting on Hitler's deeds. Our intention here was to respect the fact that many academics are hired and promoted (mainly) on the basis of the quality, quantity, and reception of the published work attributed to them. It makes sense for academics to care deeply about whether their work is attributed to them and whether it is being altered without their knowledge.

The non-commercial part of the license means that the work cannot be used for the purposes of making money (without the authors' express consent). This protects authors from third parties commercializing their ideas. The authors of 
this chapter have both been involved in commercializing academic research, and so we understand that many researchers wish to protect their valuable ideas, either to control how the research is put into practice, or to profit from it themselves. Some psychological scales, for example, are sold to mental health practitioners, generating profits for the authors of those scales. If a scale were published in an open access journal that did not have the non-commercial clause, then the scale could be used commercially by a third party without the permission of the authors. We believe that the non-commercial clause offers an, admittedly thin, layer of protection against third parties capitalizing off our authors work. We hope that this thin layer of protection might encourage authors to publish their research when it is finished, rather than after they have fully commercialized it. Importantly, though, we prefer this protection to be 'thin, rather than a more robust copyright policy available from most academic publishers. Since this is a Creative Commons non-commercial license it does allow for research published in the IJW to be used by non-commercial groups without the authors' permission (as long as they attribute it to the author and do not make new versions of it). In line with our belief in the point of academic research being to create useful information for all (and essentially make the world a better place), we hope that the research we publish will be used (in a charitable or non-profit manner) to help people in need. Our main aim is to avoid the situation of some very useful research being published, but no one being able to put it to use because the authors have not put it to use.

So far, no authors have complained about our use of the Creative Commons BY-NC-ND license. A few authors have been pleased about how easy it is for them to use their work in other ways. For example, authors can host the original or adapted versions on their own website, reproduce the article in an anthology or monograph, or even print and bind it nicely and sell it as 'a good birthday present for the intellectual in your life.' All we ask is that they acknowledge that the IJW was the original publisher.

\section{The prestige barrier and the open access solution}

\section{The prestige barrier}

Given all of the arguments above, we knew that we wanted to create an interdisciplinary online only platinum open access journal on wellbeing (broadly construed, including disciplines such as philosophy, psychology, economics, and sociology). We also desired for the journal to be an exceptional one; a high quality well-respected journal that leading academics would be proud to publish their work in. As junior academics, we were confronted with a huge prestige problem; why would the best scholars in the field want to join our editorial team or submit their research to us? These concerns cannot be understated. While all academics feel the pressure to publish in the most well-known 
journals, young academics feel it acutely. In many disciplines and universities, research publications count for hiring, tenure, and promotion only if they appear in an often implicit, but usually set, list of journals. New journals cannot be on those lists straight away, and are only likely to make it onto those lists after they prove themselves through publishing top quality research. Soliciting excellent research is difficult when your journal is not already on that list. Academic prestige, the promise of academic excellence achieved by association with perceived academic excellence, is the key to attracting those initial top quality submissions.

Unfortunately for us, academic prestige also tends to favor established ways of thinking and operating. All of our buzzwords (open access, interdisciplinary, online only, and wellbeing) are relative newcomers to academia, which made us think that they were more likely to raise 'prestige red flags' than our chances of getting the IJW off the ground. Both being educated and working in New Zealand, rather than at an Ivy League university in the US, we did not have institutional prestige to leverage. Aaron had a few contacts with excellent psychologists working on wellbeing, but other than that, there was no reason to think we had the resources to resolve our prestige problem. If we were flexible on our platinum open access status, then we might have been adopted by an established journal publisher. Being associated with Elsevier or Taylor and Francis might have allayed fears that the IJW would only be read by people who accidentally found the page via a procession of typos. However, our principles insisted that we did not give up on platinum open access. So, armed with just a few contacts, and an overabundance of naïve optimism and caffeine, we pushed ahead with our idea.

\section{The open access solution}

Before too long, we were joined by our third co-editor, rising star in economics, Nattavudh Powdthavee. We then created a 70-page business plan that stressed the low cost of online publishing (even of the highest quality), and the IJW's main point of difference - being fully open access. Then began the nervewracking process of contacting our academic idols, explaining the rationale and the mandate of the IJW, and inviting them to join our editorial team. To our surprise, nearly all of the academics we contacted enthusiastically agreed to not just put their names to the IJW, but also to offer their time and effort in many different ways. In a matter of weeks, our editorial and advisory boards were brimming with many of the best established and up-and-coming researchers in the field. All of a sudden, we found ourselves with the support of people who could resolve our prestige problem, and provide us with invaluable advice on editing and publishing.

But why were they all so eager to get on board with us, two novice academics from New Zealand? For the vast majority of our now colleagues, and especially the more established ones, the main attraction was our fully open 
access publishing model. Many of them shared our disgruntlement at some of the academic publishers' prices and other practices. They saw supporting the IJW as something they could do to help turn the tide back toward the ideal of making useful information available to everyone, and not double or triple-charging the academic institutions aiming to achieve this goal. World renowned wellbeing expert and IJW advisory board member, John Helliwell, for example, made it very clear to us that his tremendous efforts to help establish and promote the IJW were motivated by our commitment to platinum open access publishing.

With the support of John Helliwell, and other leaders in the field of wellbeing research, we were able to attract enough funding to cover the IJW's start up and operating costs for at least eight years. Initially, technical and webhosting support was provided by the Open Polytechnic of New Zealand, and funding for professional copyediting, layout editing and proofreading was generously provided by the Vic Davis Memorial Trust (a mainly community-based mental health funding organization in New Zealand). After two years of invaluable service, Nattavudh relinquished his co-editorial role, and was replaced by Stephen $\mathrm{Wu}$ from Hamilton College in New York. The operations of the IJW are now generously funded by Hamilton College, who showed interest in the journal because of its topic, early success, and open access status. Shortly after, Lindsay Oades, psychologist at the University of Melbourne Australia, also joined our co-editorial team and brought with him much policy and process experience. After we attracted so many leading wellbeing scholars to help run the journal, it was clear that the prestige problem had been overcome, and perhaps even turned right around. In fact, reflecting back to the very first issue of the IJW, we attracted such esteemed scholars as Martin Seligman, Fred Bryant, John Helliwell, Erik Angner, and featured an interview with Nobel laureate Daniel Kahneman. As such, institutions have become enthusiastic about aligning with and funding the IJW, especially considering it is cheap to do so. As a result, we have published 113 articles and reviews over the last five years.

While many things go into creating a successful journal, the moral of this story is that a commitment to platinum open access publishing is what made the difference between us creating a one-issue-wonder and the globally read and increasingly influential IJW.

\section{Has the IJW made a difference?: Opening up wellbeing studies}

\section{Affiliation troubles}

Although some measures of the IJW's impact have already been mentioned, we'd like to emphasize the many ways in which the IJW has helped to open up wellbeing studies. In the publish-or-perish world that emerging academics struggle to survive in, losing an affiliation with an academic institution is 
often the death knell for an academic career. Unaffiliated scholars are less likely to be invited to conferences, have their manuscripts accepted for peer review, and be invited to interview for academic positions. To make matters worse, they also have their access to the latest research nearly completely cut off. They will unlikely be able to afford to read many articles, especially at approximately US\$40 an article. Sure, the unfortunate unaffiliated academics could approach authors directly, and ask for pre-prints, but if they are conducting serious research then they would be sending such requests almost daily. It might be argued that this inconvenience only affects a small number of people, since the half-life of unaffiliated scholars is relatively short. However, many affiliated scholars find themselves in a similar situation. Academics affiliated to institutions outside of the West, and even the less established ones in the West, will rely on libraries that are struggling to keep up with the rising cost of bundles of journals. A recent Harvard University memo revealed that their library is struggling to pay for subscriptions to scientific journals, which now cost upwards of US\$3.5million. ${ }^{6}$ Furthermore, a very similar story can be told about unaffiliated and less-fortunately-affiliated scholars and author fees.

The beauty of platinum open access publishing is that these problems disappear. As long as the article is of sufficient academic merit, it can be published in the IJW (18\% of submitted articles were accepted in 2015), and then disseminated around the world for everyone to read without requiring the author to pay a US\$3,000 gold open access fee. For example, emerging academic Rachel Dodge, and her co-authors, submitted an article to us from a partially affiliated position. At the time Dodge submitted 'The Challenge of Defining Wellbeing' to the IJW, she was a part time PhD student at Cardiff Metropolitan University in the United Kingdom. Since we did not evaluate the submission on its authors' affiliations, or its lead author's position in the academic hierarchy, and since there were no submission or author costs, Dodge encountered no barriers to publishing her work with the IJW. After review and subsequent revisions, the paper was published in 2012. As a very junior academic - a part time studentDodge did not expect that her research would make much of an impact in her own country, let alone the world. However in a little over three years, her article 'The Challenge of Defining Wellbeing' has been viewed over 50,000 times in at least 96 countries, including multiple views in places such as Iran, Rwanda, and Peru. The combination of the IJW's online and free and unrestricted access policies truly makes the academic research we publish available around the world. Furthermore, most academics do not just want their research to be read by a lot of people, they also want their research to impact the relevant scholarly debates. Fortunately, given academics' propensity to do their research online using search engines like Google Scholar, open access research is readily accessible to all academics, including those at privileged research institutions. The truth of this is perhaps best evidenced by the fact that (according to Google Scholar) 'The Challenge of Defining Wellbeing' has been cited 151 times in just over three years. ${ }^{7}$ 


\section{Opening up the discipline to new readers}

To further take advantage of the IJW's broad accessibility, our second issue was aimed at scholars from all disciplines and educated non-academics. 'Felicitators,' as it was called, was designed to act as an entry point to academic research on wellbeing for academics and laypeople alike. The Felicitators issue effectively made interdisciplinary research on wellbeing more open by placing an even greater emphasis on doing away with unnecessary disciplinary jargon and focusing on real world examples. The issue included articles from a diverse range of authors, including an artist, a philosopher, a monk, a historian, and social scientists. The issue also covered an eclectic range of topics, including Montessori education, Dr Seuss's The Lorax, a Singaporean prison, a music teacher's inclusive approach, Bruder Klaus on peace and war, and an investigation of whether Moses was happy. We were very pleased to enable the publication of academic work that we could whole-heartedly direct our non-academic friends and family towards, in full knowledge that the articles would be accessible to them (in both senses of the word; i.e., free and understandable). We liked the Felicitators idea because it was open in these ways, but we could not have published it if the IJW was not open as well. As independent publishers, we the co-editors of the IJW, were free to decide what we would publish, and in what format we would publish it. We are free to open up existing publishing practices and help produce issues that might not otherwise be published in a venue that is accessible to academics and lay people.

\section{Open access: Into the future}

\section{Could the IJW be more open?}

When setting up the IJW, we also considered other ways that the journal might be more open. We currently encourage authors to provide data and qualitative transcripts, which we publish as supplementary files. When authors publish their source data and qualitative transcripts, other researchers can use and challenge them, moving the boundaries of shared knowledge more quickly and transparently. We decided not to mandate the publication of source data in the end because we feared that the majority of authors are not ready to share their data and open themselves up to criticism and the possibility of being scooped on future publications. However, we hope that the funders of research will start to mandate that all data sources are published in open access venues alongside the research articles based on them.

The IJW editors also considered an open review policy, according to which reviews of articles are published along with the articles themselves. Sometimes reviewers names are included, and sometimes not. The transparency benefits of these kinds of policies are very appealing. The robustness of peer review would 
be visible to everyone. It is also argued that open review could help reward the currently thankless task of reviewing the manuscripts of others. Again, we decided that the key stakeholders were not ready; we believed that most academics are so busy that they would be much more reluctant to agree to review an article publically. Being so busy means that most academics will worry that the review will take longer because producing a mistake-free review that is polished enough for public consumption will take twice as long as a regular review would. Furthermore, if reviews have the reviewers' names attached, this could reflect very badly on them if they make a mistake, again putting pressure on them to spend much more time on the review. All this extra time that reviewers might spend on reviews seems like a point in favor of open reviews, and it is from the big picture perspective, but it is seen as a disincentive for most reviewers. We figured that academics are already less likely to review for a new journal, so we decided against applying this further pressure on reviewers. It seems that only a massive re-organizing of several academic institutions could help resolve this problem, something like centralizing all potential reviewers and balancing their reviewing workloads, but such huge changes might introduce new problems.

The IJW could be more open, and being more open in the ways just mentioned would probably provide the most benefit. Unfortunately, our view is that at the present time academics themselves do not quite seem ready for this level of openness. Perhaps in the next decade we will see a cultural shift regarding this extreme openness, but it is more likely that academics will need to be nudged or coerced by funding institutions before they become more receptive to opening up peer review and their source data. When we feel like our most important stakeholders are ready, the IJW will happily adopt these more open policies.

\section{What now for the IJW?}

The IJW now has a great team of enthusiastic people involved, the software is robust and well managed and maintained, funding has been obtained for at least the next three years, and the disciplinary reach of the journal and the impacts of the work it publishes are further increasing. Looking into the future, we can see that the IJW, buoyed by its commitment to open access, will go from strength to strength. It is no wonder that we have been approached by major journal publishers who would like the IJW on their books. But, the IJW is not a commercial venture; it is an academic venture with the aim to disseminate useful information on wellbeing as widely and as openly as possible, and a commitment to open access.

Naturally, we still have many challenges ahead, such as keeping a pace with publishing trends and newer tracking technologies, sheer volume of submissions, more thoroughly indexing the journal with databases and search engines, 
and making sure we are not mistakenly thrown in with the new explosion of fake open access journals. But as for now, the IJW is still running well on all the hard work and enthusiasm of the open-access-inspired academics and others involved, and the coffee of course, which continues to flow. We would like to take this opportunity to thank all of the academics who find the time to help produce and disseminate quality research through platinum open access channels - together we are making a positive difference.

\section{Notes}

${ }^{1}$ International Journal of Wellbeing, n.d.

${ }^{2}$ Prices are readily available on www.springer.com. Visit any normal ('Open Choice') Springer journal when you do not have a subscription, and check the price to download an article.

${ }^{3}$ Open Choice prices and information are readily available here: http://www. springer.com/gp/open-access/springer-open-choice.

${ }^{4}$ See all Springer journal subscription prices here: https://www.springer. com/gp/librarians/journal-price-list.

${ }^{5}$ See http://www.springer.com/gp/open-access/springer-open.

${ }^{6}$ See, for example, https://www.theguardian.com/science/2012/apr/24/ harvard-university-journal-publishers-prices.

7 The Web of Science citation tracker, which includes only select scientific journals, notes 28 citations of 'The Challenge of Defining Wellbeing' as at 12 March 2016. The 151 citations in Google Scholar was also as at 12 March 2016. 